\title{
Pharmacology and Inotropic Potential of Forskolin in the Human Heart
}

\author{
Michael R. Bristow, Robert Ginsburg, Arthur Strosberg, \\ Wayne Montgomery, and Wayne Minobe \\ Division of Cardiology, Stanford University School of Medicine, \\ Stanford, California 94305; Syntex Research Laboratories, \\ Palo Alto, California 94300
}

bstract. We evaluated the effects of the diterpene compound forskolin in human myocardial adenylate cyclase preparations, isolated trabeculae and papillary muscles derived from failing human hearts, and acutely instrumented dogs. Forskolin was a potent, powerful activator of human myocardial adenylate cyclase and produced maximal effects that were 4.82 (normally functioning left ventricle) and 6.13 (failing left ventricle) fold greater than isoproterenol. In contrast to isoproterenol, forskolin retained full activity in membrane preparations derived from failing hearts. In cyclase preparations, forskolin demonstrated unique substrate and $\mathrm{Mg}^{2+}$ kinetic properties that could be distinguished from hormone receptor-coupled agonists or fluoride ion. The adenylate cyclase stimulatory effect of forskolin was synergistic with isoproterenol, apparently due to the location of forskolin activation being beyond the level of hormone receptor-agonist in the receptor-cyclase complex. Forskolin was a potent positive inotrope in failing human myocardium, producing a stimulation of contraction that was similar to isoproterenol. Finally, in open chest dogs forskolin was a positive inotropic agent that reduced preload and afterload. We conclude that forskolin belongs to a class of agents that may have therapeutic potential in the treatment of congestive heart failure.

\section{Introduction}

The diterpene derivative forskolin (Fig. 1) is a potent activator of adenylate cyclase systems $(1,2)$, including myocardial ade-

Address reprint requests to Dr. Bristow, Division of Cardiology, University of Utah Medical Center, Salt Lake City, UT 84132.

Received for publication 2 December 1983 and in revised form 7 February 1984

J. Clin. Invest.

(c) The American Society for Clinical Investigation, Inc.

$0021-9738 / 84 / 07 / 0212 / 12 \$ 1.00$

Volume 74 , July 1984, 212-223 nylate cyclase (1). In broken cell preparations, this unique compound may directly stimulate the catalytic moiety $(C)^{1}$ of adenylate cyclase without interacting with $\mathrm{N}$, the guanyl nucleotide regulatory subunit of cyclase (3).

Compounds that stimulate cyclic AMP (cAMP) production increase the contractile state of the heart $(4,5)$. In the human heart the most potent pharmacologic agents in this regard are catecholamines that possess $\beta$-adrenergic agonist activity (6), and both intravenous $(7-11)$ and orally effective $(12,13)$ $\beta$-agonists have been used in the treatment of heart failure.

Despite their potency and initial efficacy, $\beta$-adrenergic agonists have one major pharmacologic disadvantage that limits their long-term use. Continuous exposure to catecholamines renders the myocardium subsensitive to $\beta$-adrenergic stimuli $(12,14)$ by reducing $\beta$-receptor density $(6,14-18)$ and/or receptor-cyclase coupling (15-18). Both of these subsensitivity phenomena aré apparently regulated through $\mathrm{N}$, as mutant cells that do not possess $\mathrm{N}$ do not exhibit subsensitivity phenomena $(19,20)$.

It follows that pharmacologic agents that act primarily on C should not demonstrate catecholamine-type subsensitivity phenomena. These agents should also be positive inotropic agents, through activation of myocardial adenylate cyclase $(4,5)$. Forskolin does appear to possess positive inotropic activity, on the basis of previous work in isolated guinea pig left atrium $(1,21)$.

In this investigation we give the first description of the effects of forskolin in tissue derived from failing or normally functioning human heart, and the first detailed analysis of the pharmacologic effects of forskolin on myocardial adenylate cyclase. In the human heart forskolin exhibits positive inotropic characteristics similar to isoproterenol. However, unlike isoproterenol, forskolin is capable of producing maximal adenylate cyclase responses in myocardial membranes that demonstrate catecholamine subsensitivity secondary to $\beta$-adrenergic receptor down-regulation. Moreover, forskolin and $\beta$-adrenergic agonists exhibit synergistic effects on adenylate cyclase stimulation and additive effects on

1. Abbreviations used in this paper: $\mathrm{C}$, catalytic moiety of adenylate cyclase; DHA, dihydroalprenolol; Gpp(NH)p, nonhydrolyzable GTP analogue 5'-guanyl imidodiphosphate; GTP, guanosine triphosphate; ICYP, iodocyanopindolol; $\mathrm{N}$, guanyl nucleotide regulatory subunit of adenylate cyclase. 
<smiles>CCC1(C)CC(=O)C2(C)C(C)(O1)C(OC(C)=O)C(O)C1C(C)(C)CCC(O)C12C</smiles>

Figure 1. Forskolin.

force development; this suggests that combinations of forskolin and $\beta$-agonists might be an effective inotropic intervention.

\section{Methods}

Human myocardial tissue was obtained from cardiac transplant recipients and potential donors. For biochemical studies, normally functioning left ventricular myocardium was obtained from six subjects with brain death who were maintained on respirators for periods of 2-10 d before cardiac excision. None of these subjects had experienced cardiac symptoms, and all were vigorous, young (average age $30 \mathrm{yr}$ ) males before suffering fatal head injury $(n=5)$ or idiopathic cerebral edema ( $n$ $=1)$. Five of the six subjects were considered suitable cardiac transplant donors before the detection of factors excluding the graft (tricuspid endocarditis in one, atrial laceration in one) or late exclusion of wouldbe recipients for acute medical complications $(n=3)$. Two hearts were procured off-site (22), and four on-site. Additional normally functioning left ventricular myocardium was obtained from two heart-lung transplant recipients who were females with right ventricular failure secondary to primary pulmonary hypertension, ages 45 and 36 . The mean age for subjects in the normal cardiac function group was $31.5 \pm 3.4 \mathrm{yr}$.

Failing human myocardium was obtained from eight transplant recipients with New York Heart Association (NHHA) class IV failure. These transplant recipients were four females and four male subjects who received transplantation because of idiopathic cardiomyopathy $(n=6)$ or end-stage coronary disease $(n=2)$. The mean age of these subjects was $30.2 \pm 4.8$ years $(P=$ NS compared with the group with normal left ventricular function), mean cardiac index was $1.51 \pm 0.15$ liters/min per $\mathrm{m}^{2}$, and the mean left ventricular diastolic pressure was $25.8 \pm 3.4 \mathrm{mmHg}$.

In transplant recipients and on-site donors the hearts were excised and immediately immersed in ice-cold, oxygenated physiologic salt solution. Two tissue aliquots were taken from each left ventricle: a 4-6-g sample for $\beta$-adrenergic receptor preparations and a 2-g sample for adenylate cyclase preparations (22). Tissue was homogenized and prepared for receptor binding and adenylate cyclase assays, as previously described $(14,22)$. The elapsed time between cardiac excision, weighing, and homogenization was $<30 \mathrm{~min}$ in all cases. In distantly procured hearts the time between cardiac excision and homogenization was under $2 \mathrm{~h}$.

Measurement of responses of isolated failing human cardiac tissue was as described previously $(22,23)$. Hearts were removed from cardiac transplant recipients with class IV, end-stage heart failure. These subjects did not differ from subjects used for biochemical studies in age, functional class, or hemodynamic parameters (all $P=\mathrm{NS}$ ). 12 papillary muscles and trabeculae from the free wall of the right ventricle were removed and dissected to a uniform size of 6-7 $\mathrm{mm}$ in length and $1 \mathrm{~mm}$ in diam. Each muscle was then attached to a force-displacement transducer (Gould,
UC-3) by means of a gold chain attached to two plastic clips and placed in separate $100-\mathrm{ml}$ tissue baths containing physiologic salt solution at a pH of 7.40-7.45 and a temperature of $37^{\circ} \mathrm{C}$. Isometric contraction was generated by field stimulation through platinum electrodes placed parallel to the long axis of the muscle that delivered a 3-ms square wave impulse at $10 \%$ above threshold at a rate of $0.6 \mathrm{~Hz}$. The initial muscle length of each strip was adjusted to obtain the maximal isometric tension. The actively developed tension was calculated as the difference between the peak tension during a contraction (total tension) and the resting tension. The resting tension or preload was between 1.0 and $1.5 \mathrm{~g}$ in all cases. All recordings were made on a 12-channel recorder with lightsensitive paper. The tissue was equilibrated in the physiologic salt solution for 60-90 min. For determination of isoproterenol or forskolin concentration-response curves, increases in concentration of agonist between $10^{-9} \mathrm{M}$ and $10^{-4} \mathrm{M}$ were added in a cumulative fashion.

$\beta$-adrenergic receptor density and antagonist affinity were determined by $\left[{ }^{3} \mathrm{H}\right]$-dihydroalprenolol $\left(\left[{ }^{3} \mathrm{H}\right] \mathrm{DHA}\right)$ binding, in freshly prepared membranes, as previously described (22). Crude myocardial membranes prepared by extraction of contractile proteins were incubated as 1.5$3.0 \mathrm{mg} / \mathrm{ml}$ of membrane protein in $75 \mathrm{mM}$ Tris, $10 \mathrm{mM} \mathrm{MgCl}, 1 \mathrm{mM}$ ascorbic acid, $\mathrm{pH} 7.5$, buffer in a total volume of $450 \mu \mathrm{l}$ for $30 \mathrm{~min}$ at $30^{\circ} \mathrm{C}$. $\left[{ }^{3} \mathrm{H}\right] \mathrm{DHA}$-bound to $\beta$-adrenergic receptors was trapped by vacuum filtration; and specific binding was defined as that displaceable by $10^{-3}$ $\mathrm{M}$ isoproterenol.

Adenylate cyclase activity was measured in myocardial membranes as previously described $(14,22)$. Membrane preparations were stored at $-70^{\circ} \mathrm{C}$ for $2 \mathrm{wk}$ to $7 \mathrm{mo}$ before assay. Preparations from failing $(n=8)$ and normally functioning left ventricle $(n=8)$ were paired by matching preparations for length of storage, which did not differ in any case by over $5 \mathrm{wk}$. Assay tubes containing $75-250 \mu \mathrm{g} / \mathrm{ml}$ of membrane protein, $100 \mathrm{mM}$ Tris buffer, $\mathrm{pH} 7.40,10^{-5} \mathrm{M}$ GTP, $10 \mathrm{mM}$ phosphocreatine, $1 \mathrm{mM}$ cAMP, $0.1 \mathrm{mM} \mathrm{MgATP}$, and $0.5 \mathrm{mM} \mathrm{MgCl}_{2}$ were prepared in cryogenic racks at $0^{\circ} \mathrm{C}$. After a 5-min warm-up period the reaction measurement was begun by trace-labeling the ATP pool with $1.0-2.5 \mu \mathrm{Ci}$ of $\left[\alpha^{-32} \mathrm{P}\right] \mathrm{ATP}$, to give a final assay volume of $250 \mu \mathrm{l}$. $\left[{ }^{32} \mathrm{P}\right] \mathrm{cAMP}$ formed over a 20 -min period at $30^{\circ} \mathrm{C}$ was subsequently isolated by Dowex-alumina chromatography.

The effect of forskolin on $\beta$-adrenergic receptor density, antagonist affinity, and agonist affinity was determined in freshly prepared guinea pig myocardial membranes prepared from whole right and left ventricular preparations derived from 700-900-g male Hartley albino guinea pigs. Membranes were prepared as described in "Method A" of a previous communication (22). Receptor density and antagonist affinity were determined by $\pm\left[{ }^{125} I\right]$ iodocyanopindolol $\left(\left[{ }^{125} \mathrm{I}\right] \mathrm{CYP}\right)$ binding according to the method of Engel et al. (24), except that experiments were conducted at $30^{\circ} \mathrm{C}$ with an incubation time of $120 \mathrm{~min}$ (equilibrium reached at $105 \mathrm{~min})$. The buffer for $\left[{ }^{125} \mathrm{I}\right] \mathrm{CYP}$ binding was $150 \mathrm{mM}$ $\mathrm{NaCl}, 20 \mathrm{mM}$ Tris, $\mathrm{pH} 7.5$, with a membrane protein concentration of $100-200 \mu \mathrm{g} / \mathrm{ml}$. Specific binding was defined as that displaceable by $1 \mu \mathrm{M}(-)$-propranolol. Other details of the $\left[{ }^{125} I\right] C Y P$ binding were identical to the $\left[{ }^{3} \mathrm{H}\right] \mathrm{DHA}$ methods. Guinea pig myocardial membranes were prepared for cyclase assays by homogenizing $100-150 \mathrm{mg}$ of left ventricle, according to methods described for cyclase preparations in human hearts.

The effect of forskolin on receptor density and antagonist affinity in myocardial membranes derived from failing human left ventricle was assessed by $(-)\left[{ }^{125} \mathrm{I}\right] \mathrm{CYP}$ binding (25), with assay conditions identical to $( \pm)\left[{ }^{125} \mathrm{I}\right] \mathrm{CYP}$ binding in guinea pig preparations and other methods identical to $\left[{ }^{3} \mathrm{H}\right] \mathrm{DHA}$ binding as described above. Experiments were performed in membranes stored for periods up to $5 \mathrm{mo}$ in $250 \mathrm{mM}$ sucrose, $50 \mathrm{mM}$ Tris, $1.0 \mathrm{mM}$ EGTA, pH 7.5 buffer at $-70^{\circ} \mathrm{C}$. Protein was measured by the method of Lowry (26). 
Myosin was measured by acrylamide-slab gel electrophoresis, as previously described (22). Maximum [ $\left.{ }^{3} \mathrm{H}\right] \mathrm{DHA}$ or $\left[{ }^{125} \mathrm{I}\right] \mathrm{CYP}$ binding $\left(B_{\max }\right.$ receptor density) and antagonist dissociation constants $\left(K_{d}\right)$ were determined from Scatchard plots (27) of six to eight increasing concentrations of radioligand between 0.5 and 3-4 $\times K_{\mathrm{d}}$. In cyclase assays, substrate maximum velocity $\left(V_{\max }\right)$ and Michaelis constant $\left(K_{\mathrm{m}}\right)$ and $\mathrm{Mg}^{2+} V_{\max }$ and dissociation constant $\left(K_{\mathrm{a}}\right)$ were determined from Hanes plots (28) of substrate/velocity vs. substrate where $V_{\max }=1 /$ slope and $K_{\mathrm{m}}=-x$ intercept. In measurements of MgATP (substrate) kinetics the $\mathbf{M g}^{2+}$ concentration was $0.5 \mathrm{mM}$, and in $\mathbf{M g}^{2+}$ kinetic experiments the MgATP concentration was $0.1 \mathrm{mM}$. In ['25I]CYP-agonist competition experiments agonist affinity was determined by computer analysis, using a four-parameter logistic equation (29) and a DEC-PDP computer (Digital Equipment Corp., Maynard, MA).

For hemodynamic studies conducted in open-chest dogs, mongrel dogs weighing 9.9-12.5 kg were anesthetized with sodium pentobarbital $(30 \mathrm{mg} / \mathrm{kg}$ i.v.) and supplemented hourly with a total of $5 \mathrm{mg} / \mathrm{kg}$ i.v. An endotracheal tube was inserted and each dog was ventilated for the duration of the experiment with a respirator (Harvard Apparatus Co., Inc., S. Natick, MA). After a midline thoracotomy, aortic flow was monitored by a Statham electromagnetic flow probe that was positioned on the ascending thoracic aorta. Left ventricular and left atrial pressures were measured by Konigsberg implantable pressure transducers respectively placed in the left ventricle (p. 6.5) through a stab wound in the apex of the heart and in the left atrium (p. 4.0) through an incision in the atrial appendage. The left ventricular pressure signal was electronically differentiated to give left ventricular $\mathrm{d} P / \mathrm{d} t$. Systemic blood pressure was measured from a cannulated femoral artery with a Statham P23 Db pressure transducer. Heart rate was recorded by a cardiotachometer triggered by the $R$-wave of a limb lead II ECG. A femoral vein was cannulated for drug administration. All data were recorded on a type B Dynograph (Beckman Instruments, Inc., Fullerton, CA).

Cardiac output (CO) was equated with aortic flow. Mean arterial

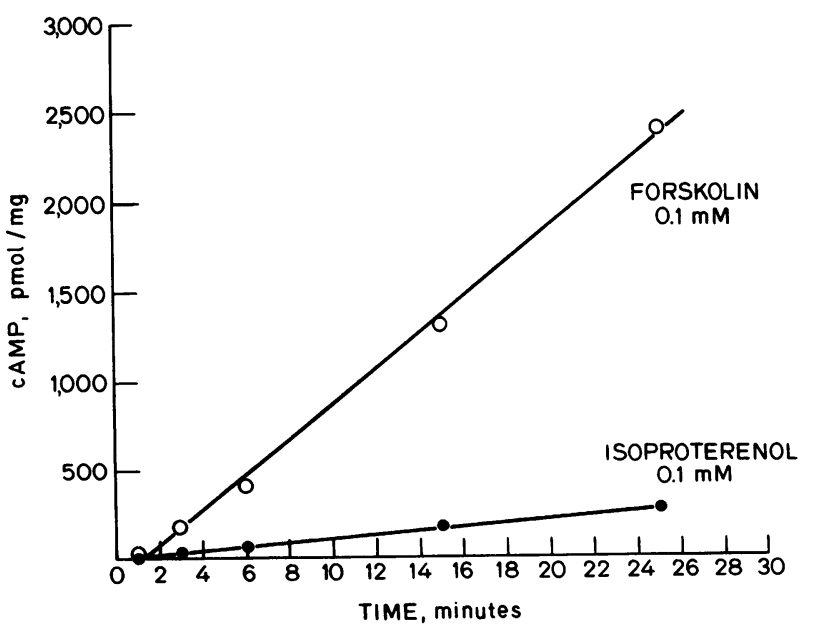

Figure 2. Time course of cAMP formation in response to $0.1 \mathrm{mM}$ forskolin (O) or isoproterenol (๑). Membrane preparation was from a normally functioning left ventricle ( $\beta$-receptor density $=46.4 \mathrm{fmol} /$ $\mathrm{mg}$ ). Experiment was conducted by prewarming membranes for 5 $\mathrm{min}$ at $30^{\circ} \mathrm{C}$ and then adding $\left[\alpha^{32} \mathrm{P}\right] \mathrm{ATP}$ and agonist. Guanine nucleotide concentration was GTP $10^{-5} \mathrm{M}$. Points are means of duplicate values.

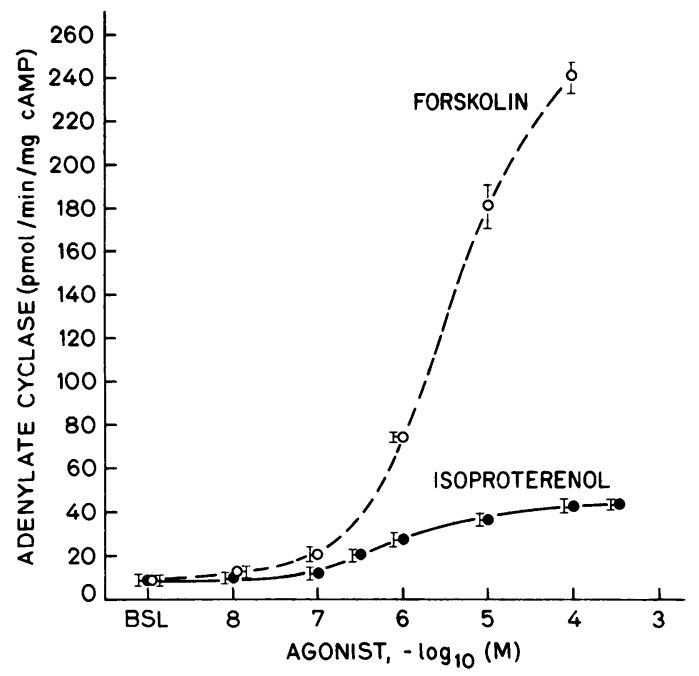

Figure 3. Effect of forskolin (0) or isoproterenol (•) on cAMP formation, individual experiment in membranes derived from normally functioning human left ventricular myocardium. $\beta$-receptor density $=76.3 \mathrm{fmol} / \mathrm{mg}$. Points are means of triplicate values \pm SEM. BSL, basal activity with $\mathrm{H}_{2} \mathrm{O}$ instead of isoproterenol.

pressure (MAP) was calculated as the diastolic pressure plus one-third the pulse pressure. Total peripheral resistance (TPR) was calculated according to the formula TPR $=($ MAP $\times 80)+C O($ liters per minute $)$ and expressed in units of dynes $\cdot$ seconds $\cdot$ (centimeters) ${ }^{-5}$.

Isoproterenol and forskolin dose-response curves were measured in each dog. Each drug was administered by intravenous infusion $\left(0.2 \mathrm{~cm}^{3} /\right.$ $\mathrm{min}$ ) in an ascending-dose fashion, with each dose level infused for 5 min. Isoproterenol was dissolved in saline and infused at 0.01-31.6 $\mathrm{nmol} / \mathrm{kg}$ per min, while forskolin was dissolved in propylene glycol and infused at $1-100 \mathrm{nmol} / \mathrm{kg} / \mathrm{min}$. This amount of propylene glycol had no effect on hemodynamics.

Statistical analysis of differences between two means was by the unpaired or paired $t$ test, with a $P<0.05$ in the two-tailed distribution considered to be statistically significant.

\section{Results}

Effects of forskolin on myocardial adenylate cyclase. Forskolin is a potent activator of human adenylate cyclase, as shown in Figs. 2 and 3. Temporal kinetics of forskolin activation of adenylate cyclase are shown in Fig. 2. After a brief lag period, forskolin rapidly activated cAMP production, with a time course that was similar to isoproterenol. Relative to isoproterenol, forskolin produced a 4.82 (normal heart) or 6.13 (failing heart) times greater maximal stimulation (Fig. 3 and Table I) and was active over the same concentration range. Unlike isoproterenol, forskolin did not appear to approach a true maximum at higher concentration ranges, and stimulated cAMP production in a linear-log dose manner between $10^{-7}$ and $10^{-4} \mathrm{M}$. Results similar to those presented in Figs. 2 and 3 were obtained in two additional preparations.

Information on the manner in which forskolin activates adenylate cyclase was sought by examining substrate (MgATP) 
Table I. Comparison of Adenylate Cyclase Stimulation and Beta Adrenergic Receptor Density in Normal and Failing Human Left Ventricle

\begin{tabular}{|c|c|c|c|c|c|c|c|c|c|}
\hline \multirow[b]{3}{*}{ Group } & \multicolumn{6}{|c|}{ Adenylate cyclase } & \multicolumn{3}{|c|}{$\beta$-Adrenergic receptor } \\
\hline & \multirow{2}{*}{$\begin{array}{l}\text { Basal } \\
\text { activity }\end{array}$} & \multicolumn{3}{|l|}{ Net stimulation } & \multicolumn{2}{|c|}{ Increment of $\mathrm{F}^{-}$stimulation } & \multirow[b]{2}{*}{ Density $\ddagger$} & & \multirow[b]{2}{*}{$K_{\mathrm{d}} \ddagger$} \\
\hline & & Iso & $\mathrm{F}^{-}$ & FRSK & Iso/F- & FRSK/F- & & & \\
\hline & & $\mathrm{pmol} / \mathrm{min} / \mathrm{mg}$ & $\mathrm{pmol} / \mathrm{min} / \mathrm{mg}$ & $\mathrm{pmol} / \mathrm{min} / \mathrm{mg}$ & & & fmol per $\mathrm{mg} p$ & tein myosin & \\
\hline \multicolumn{10}{|l|}{$\begin{array}{l}\text { Normal LV } \\
\text { function }\end{array}$} \\
\hline$(n=8)$ & $8.16 \pm 1.20$ & $44.05 \pm 5.30$ & $45.24 \pm 5.66$ & $212.87 \pm 33.63$ & $1.02 \pm 0.09$ & $4.63 \pm 0.42$ & $54.7 \pm 6.3$ & $118.2 \pm 12.7$ & $3.67 \pm 0.76$ \\
\hline \multicolumn{10}{|l|}{ Heart failure } \\
\hline$(n=8)$ & $6.86 \pm 0.60$ & $28.11 \pm 4.39^{*}$ & $47.59 \pm 3.46$ & $172.45 \pm 18.06$ & $0.61 \pm 0.09^{*}$ & $3.43 \pm 0.65$ & $25.7 \pm 3.6^{*}$ & $45.1 \pm 8.6^{*}$ & $4.12 \pm 1.00$ \\
\hline
\end{tabular}

Iso, $0.3 \mathrm{mM}$ isoproterenol; F, $10 \mathrm{mM} \mathrm{NaF}$; FRS, $0.1 \mathrm{mM}$ forskolin. All values are \pm SEM. Net Stimulation $=$ maximum activity - basal activity. $* P<0.05$ vs. A, $t$ test. $¥$ Receptor data from 12 of these hearts (6 normal +6 failing) were included in a previous publication (22).

and $\mathrm{Mg}^{2+}$ kinetics. Table II shows $K_{\mathrm{a}}$ or $K_{\mathrm{m}}$ and $V_{\max }$ values for three failing and three normally functioning left ventricles and for the mean values of all six preparations. Forskolin produced a dramatic dose-related increase in substrate $V_{\max }$. At lower concentrations $(0.3 \mu \mathrm{M})$ forskolin increased the MgATP
$V_{\max } 3.1$ times more in normal myocardium and 6.7 times more in failing heart than did an equal concentration of isoproterenol. At a high concentration $(0.1 \mathrm{mM})$ forskolin produced increases in MgATP $V_{\max }$ that were 15.2 and 17.7 times greater than isoproterenol in normal and failing myocardium, respectively.

Table II. Human Myocardial Adenylate Cyclase, Kinetic Data

\begin{tabular}{|c|c|c|c|c|c|}
\hline \multirow[b]{2}{*}{ Group and agonist } & \multirow{2}{*}{$\begin{array}{l}\beta \text {-Receptor } \\
\text { density }\end{array}$} & \multicolumn{2}{|l|}{ MgATP } & \multicolumn{2}{|l|}{$\mathrm{Mg}^{2+}$} \\
\hline & & $K_{\mathrm{m}}$ & $V_{\max }$ & $K_{\mathrm{a}}$ & $V_{\max }$ \\
\hline & fmol/mg protein & $m M$ & pmol cAMP $\mathrm{min}^{-1} \mathrm{mg}^{-1}$ & $m M$ & pmol cAMP $\mathrm{min}^{-1} \mathrm{mg}^{-1}$ \\
\hline \multicolumn{6}{|l|}{$\begin{array}{c}\text { Normal LV } \\
\text { function } \\
(n=3)\end{array}$} \\
\hline $\mathrm{H}_{2} \mathrm{O}$ & $62.1 \pm 8.7$ & $0.064 \pm 0.019$ & $24.22 \pm 6.73$ & $2.04 \pm 0.26$ & $79.64 \pm 2.85$ \\
\hline Iso, $0.3 \mu \mathrm{M}$ & & $0.073 \pm 0.012$ & $45.10 \pm 6.49$ & $1.04 \pm 0.07$ & $93.46 \pm 6.29$ \\
\hline Iso, $0.1 \mathrm{mM}$ & & $0.086 \pm 0.020$ & $104.69 \pm 17.76$ & $0.63 \pm 0.03$ & $132.35 \pm 13.39$ \\
\hline FRSK, $0.3 \mu \mathrm{M}$ & & $0.075 \pm 0.012$ & $141.80 \pm 29.74$ & $1.19 \pm 0.14$ & $324.17 \pm 39.66$ \\
\hline FRSK, $0.1 \mathrm{mM}$ & & $0.278 \pm 0.020$ & $1,596.22 \pm 428.95$ & $0.21 \pm 0.12$ & $620.03 \pm 68.93$ \\
\hline \multicolumn{6}{|l|}{ LV failure $(n=3)$} \\
\hline $\mathrm{H}_{2} \mathrm{O}$ & $21.5 \pm 2.7$ & $0.058 \pm 0.010$ & $18.19 \pm 5.87$ & $2.65 \pm 1.02$ & $51.51 \pm 10.88$ \\
\hline Iso, $0.3 \mu \mathrm{M}$ & & $0.053 \pm 0.007$ & $25.92 \pm 6.78$ & $1.39 \pm 0.32$ & $52.77 \pm 15.58$ \\
\hline Iso, $0.1 \mathrm{mM}$ & & $0.088 \pm 0.028$ & $62.90 \pm 17.14$ & $0.58 \pm 0.02$ & $59.09 \pm 10.40$ \\
\hline FRSK, $0.3 \mu \mathrm{M}$ & & $0.114 \pm 0.007$ & $174.75 \pm 60.37$ & $1.11 \pm 0.11$ & $197.69 \pm 44.83$ \\
\hline FRSK, $0.1 \mathrm{mM}$ & & $0.248 \pm 0.034$ & $1,114.95 \pm 384.5$ & $0.33 \pm 0.19$ & $370.27 \pm 56.60$ \\
\hline \multicolumn{6}{|l|}{$\begin{array}{c}\text { All }(n=6) \\
\mathrm{H}_{2} \mathrm{O}\end{array}$} \\
\hline $\mathrm{H}_{2} \mathrm{O}$ & & $0.061 \pm 0.010$ & $21.20 \pm 4.22$ & $2.34 \pm 0.49$ & $65.58 \pm 8.06$ \\
\hline Iso, $0.3 \mu \mathrm{M}$ & & $0.064 \pm 0.009$ & $37.43 \pm 6.27^{*}$ & $1.18 \pm 0.14^{*}$ & $78.24 \pm 12.43$ \\
\hline Iso, $0.1 \mathrm{mM}$ & & $0.087 \pm 0.016$ & $83.80 \pm 14.46^{*}$ & $0.60 \pm 0.02^{*}$ & $95.72 \pm 18.06$ \\
\hline FRSK, $0.3 \mu \mathrm{M}$ & & $0.091 \pm 0.012$ & $155.05 \pm 26.42^{*}$ & $1.16 \pm 0.09^{*}$ & $273.53 \pm 41.61^{*}$ \\
\hline FRSK, $0.1 \mathrm{mM}$ & & $0.263 \pm 0.019^{*}$ & $1,355.56 \pm 279.20^{*}$ & $0.27 \pm 0.10^{*}$ & $495.07 \pm 64.69^{*}$ \\
\hline
\end{tabular}

Iso, isoproterenol; FRSK, forskolin; LV, left ventricle. ${ }^{*} P<0.05$ vs. $\mathrm{H}_{2} \mathrm{O}$ in Group C. 
Also, the increase in MgATP $V_{\max }$ produced by forskolin was accompanied by a marked increase in the $K_{\mathrm{m}}$. Forskolin and isoproterenol both lowered the $\mathrm{Mg}^{2+} K_{\mathrm{a}}$ to a similar extent, but unlike isoproterenol, forskolin also produced a substantial increase in $\mathrm{Mg}^{2+} V_{\max }$.

The effects of guanine nucleotides on isoproterenol, fluoride ion and forskolin stimulation of adenylate cyclase are given in Fig. 4. In the absence of guanine nucleotides isoproterenol produced very little cyclase activation. In contrast, guanine nucleotides were not required for forskolin stimulation of cyclase, as the forskolin response was not potentiated by either guanosine triphosphate (GTP) or nonhydrolyzable GTP analogue $(\mathrm{Gpp}(\mathrm{NH}) \mathrm{p})$. In fact, $\mathrm{Gpp}(\mathrm{NH}) \mathrm{p}$ at $10^{-5} \mathrm{M}$ produced a small amount of noncompetitive inhibition of forskolin activity. Results identical to those in Fig. 4 were obtained in two other membrane preparations.

The effect of forskolin on adenylate cyclase was not affected by $10^{-7} \mathrm{M}$ (-)propranolol (data not shown). In contrast, this concentration of propranolol produced a 31.6-fold, parallel, rightward shift in the isoproterenol dose-response curve in myocardial preparations derived from a normal heart.

Effect of forskolin in normal and catecholamine-subsensitive myocardial membranes. $\beta$-adrenergic receptor density and antagonist affinity data in membranes derived from eight normally functioning and eight failing human left ventricles are given in Table I. Relative to membranes derived from normal hearts, membranes from failing left ventricles exhibited decreased $\beta$ adrenergic receptor density, similar to previously reported observations (22). Table I also gives the results of isoproterenol, forskolin, and fluoride ion stimulation of adenylate cyclase in membranes derived from these hearts. Isoproterenol stimulation of cyclase was diminished in membranes derived from failing hearts, in agreement with the decreased $\beta$-receptor density. In contrast, cyclase stimulation by $10^{-4} \mathrm{M}$ forskolin or $10 \mathrm{mM}$ fluoride was not different in the two groups.

Synergism of isoproterenol and forskolin. Since in membrane preparations forskolin appears to directly stimulate $C$, it would be predicted that receptor-coupled stimulation of cyclase and forskolin effects would be synergistic. This is in fact the case, as shown in Fig. 5, which shows that forskolin plus isoproterenol has greater-than-additive effects in both human and guinea pig myocardial membranes. The human preparation shown in Fig. 5 was derived from a severely failing heart with a $\beta$-receptor density that was $31 \%$ of normal; the addition of forskolin converted the attenuated isoproterenol response to a more normal appearing dose-response curve. In the experiment shown in Fig. 5 , forskolin increased the isoproterenol maximum net stimulation by 2.6 -fold and decreased the activation constant $\left(K_{\text {act }}\right)$ by 2.5 -fold. Additionally, forskolin and histamine also produced synergistic stimulation in guinea pig preparations (data not shown).

Information relative to the synergistic properties of forskolin and isoproterenol was sought in an examination of the effects of each drug alone or the combination on substrate and $\mathrm{Mg}^{2+}$ kinetics. In the preparation derived from failing human heart shown in Fig. 5, forskolin and isoproterenol in combination increased MgATP $V_{\max }$ to a greater degree than the sum of each agent's individual effects (no agonist, $\mathrm{MgATP} V_{\max }=7.22 \mathrm{pmol}$

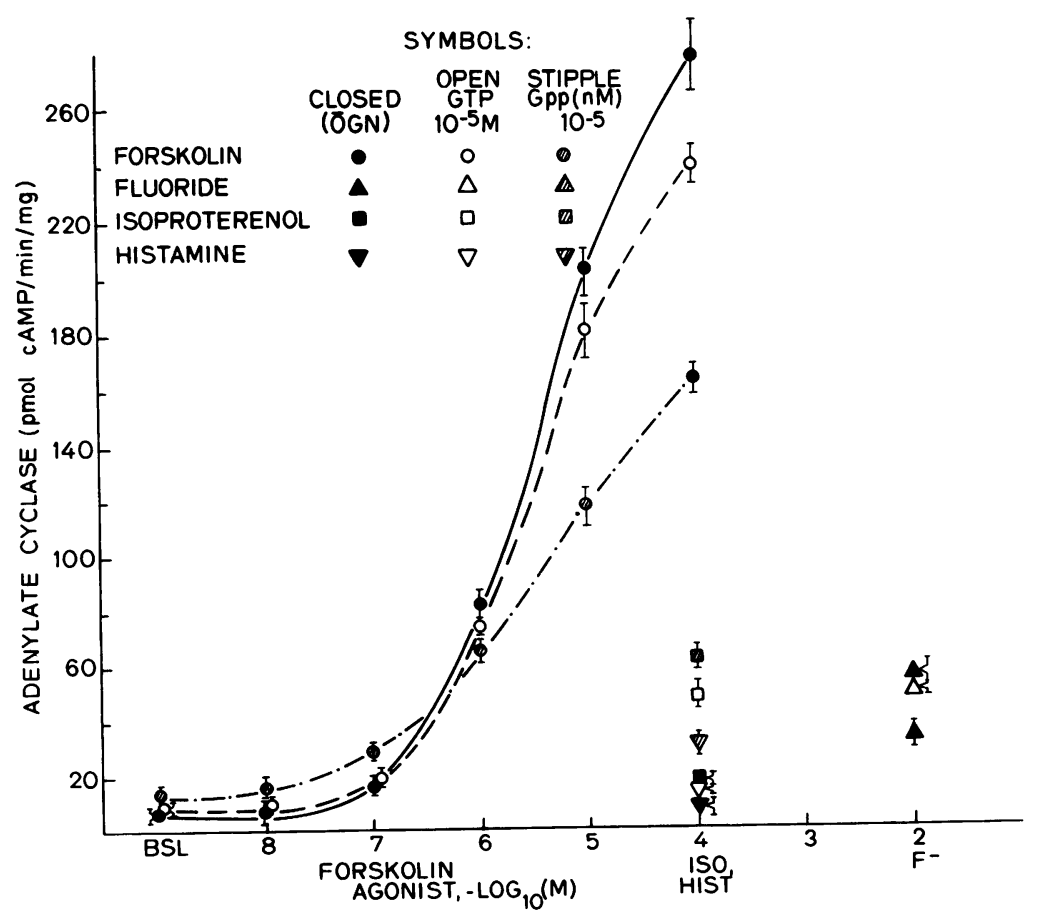

Figure 4. Effect of various agonists on adenylate cyclase activity in the absence (closed symbols [ŌGN]) or presence of $10^{-5} \mathrm{M}$ GTP (open symbols) or $10^{-5} \mathrm{M}$ $\mathrm{Gpp}(\mathrm{NH}) \mathrm{p}$ (stippled symbols). Fluoride concentration is $10 \mathrm{mM}$, isoproterenol and histamine concentrations are each $10^{-4} \mathrm{M}$. Points are \pm SEM. of triplicate values, single experiment in membranes was derived from a normally functioning left ventricle ( $\beta$-receptor density $=76.3 \mathrm{fmol} / \mathrm{mg}$ ). 
GUINEA PIG HEART
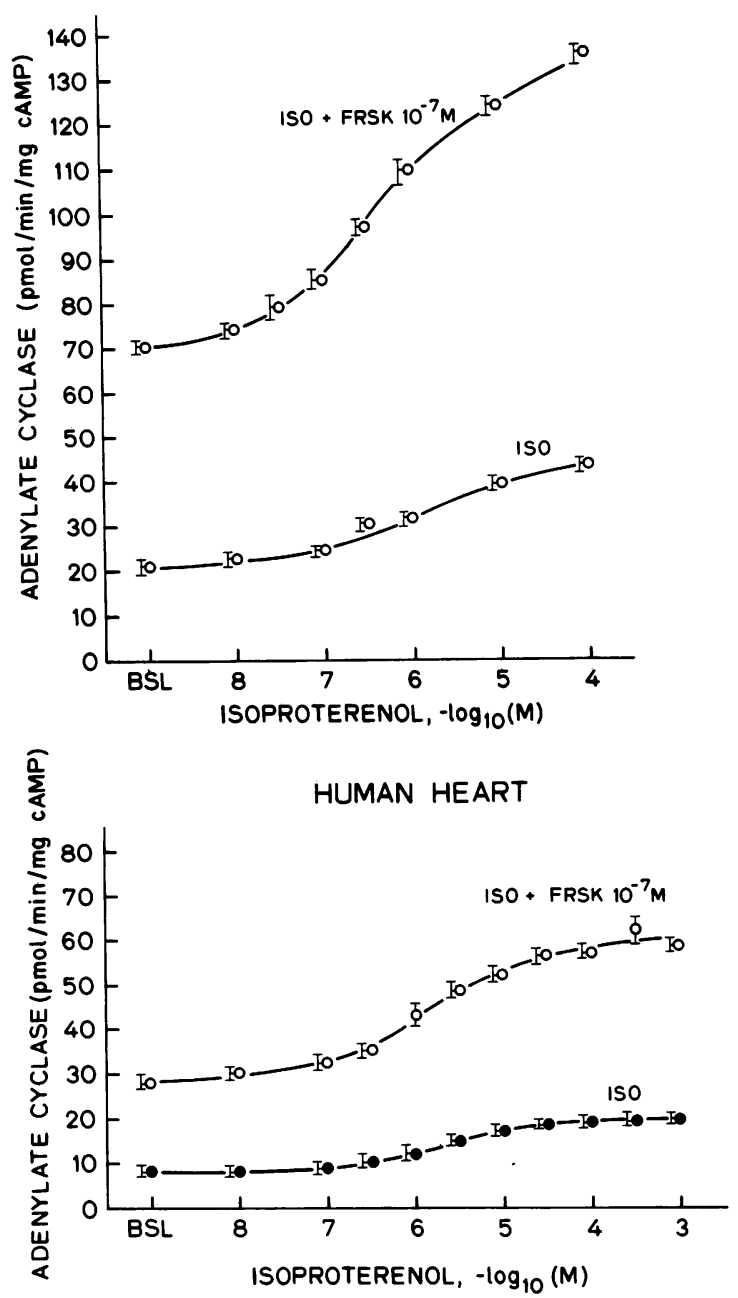

Figure 5. Effect of the addition of $10^{-7} \mathrm{M}$ forskolin (FRSK) on isoproterenol (ISO) stimulation of adenylate cyclase in membranes derived from guinea pig (upper) or severely failing human left ventricular myocardium (lower panel). BSL, basal activity with $\mathrm{H}_{2} \mathrm{O}$ in place of isoproterenol. Points are means \pm triplicate values in individual experiments. Guanine nucleotide was $10^{-5} \mathrm{M}$ GTP. The $\beta$-adrenergic receptor density in the human left ventricle was $16.9 \mathrm{fmol} / \mathrm{mg}$ protein, which is $31 \%$ of normal.

$\mathrm{cAMP} \cdot \mathrm{min}^{-1} \cdot \mathrm{mg}^{-1} ;+$ isoproterenol $10^{-4} \mathrm{M}, V_{\max }=34.72$; + forskolin $10^{-7} \mathrm{M}, V_{\max }=52.63$; + isoproterenol and forskolin, $\left.V_{\max }=131.40\right)$. Grouped kinetic data from this experiment and two other preparations derived from failing human left ventricular $(\beta$-receptor density $=21.5 \pm 2.7 \mathrm{fmol} / \mathrm{mg})$ are given in Table III, where it can be seen that the effects of forskolin and isoproterenol on MgATP $V_{\max }$ are greater than additive.

Effect of forskolin on $\beta$-receptor density and agonist affinity. As forskolin has been reported to promote formation of the high affinity agonist binding state in whole cell preparations (30), we thought it important to consider whether forskolin produced increased coupling or an increase in $\beta$-adrenergic receptor density as a potential explanation for the synergistic interaction with isoproterenol. Isoproterenol-ICYP competition curves in the presence and absence of $10 \mu \mathrm{M}$ forskolin or 100 $\mu \mathrm{M} \mathrm{Gpp}(\mathrm{NH}) \mathrm{p}$ were measured in four guinea pig and one human heart. A representative experiment in guinea pig myocardial membranes is shown in Fig. 6. The addition of $10 \mu \mathrm{M}$ forskolin did not consistently alter the isoproterenol competition curve in any experiment, whereas curves were right-shifted and steepened by the addition of $\mathrm{Gpp}(\mathrm{NH}) \mathrm{p}$ (Fig. 6). Although no analysis of the relative percent of receptor in a high affinity vs. low affinity states was performed, there was no apparent effect of forskolin on isoproterenol competition in either high or low agonist affinity ranges. In the human heart experiment forskolin had no effect on isoproterenol-ICYP binding.

In three experiments in guinea pig myocardial membranes the $\beta$-adrenergic receptor density (femtomoles per milligram) was 53.5 \pm 6.1 in the absence of forskolin and 56.2 \pm 5.1 in the presence of $10 \mu \mathrm{M}$ forskolin. $( \pm)\left[{ }^{125} \mathrm{I}\right] \mathrm{CYP} K_{\mathrm{d}}$ values (picomolar) were $29.1 \pm 3.0$ with and $64.3 \pm 0.2$ without forskolin in the assay medium. In membranes derived from four human left ventricles $10 \mu \mathrm{M}$ forskolin produced no effects on receptor density $(51.5 \pm 7.9 \mathrm{fmol} / \mathrm{mg}$ without forskolin and $49.6 \pm 8.2 \mathrm{fmol} / \mathrm{mg}$ with forskolin) or $(-)\left[{ }^{125} \mathrm{I}\right] \mathrm{CYP} K_{\mathrm{d}}(6.47 \pm 0.11 \mathrm{pM}$ without forskolin and $6.43 \pm 0.50 \mathrm{pM}$ with forskolin).

Effect of forskolin on isolated papillary muscles and trabeculae derived from failing human hearts. Forskolin produced positive inotropic effects in isolated human right ventricular trabeculae and papillary muscles derived from severely failing human hearts, as shown in Figs. 7 and 8 and Table IV. The response to forskolin differed from isoproterenol in several respects. First, as shown in Fig. 7, the inotropic response to forskolin displayed a slower onset, with a mean time to peak effect of $971 \mathrm{~s}$ compared with $103 \mathrm{~s}$ for isoproterenol (Table IV). Secondly, whereas the effect of isoproterenol was relatively shortlived (peak effect lasting $<2 \mathrm{~min}$ ), the response to forskolin was sustained for at least $45 \mathrm{~min}$ (Table $\mathrm{V}$ ). Third, the response to forskolin could be elicited 30-60 min after an initial dose of isoproterenol whereas myocardial preparations yielded little or no response to isoproterenol challenge $\mathbf{3 0} \mathrm{min}$ after giving forskolin (Table V).

Full dose-response curves to isoproterenol and forskolin were performed in isolated right ventricular papillary muscles and trabeculae from three subjects, and the mean values are shown in Fig. 8. As shown in Fig. 8, forskolin was less potent than isoproterenol on a molar basis, with a 14.6-fold difference in the median effective doses $\left(\mathrm{ED}_{50}\right.$ 's).

Maximal responses to forskolin and isoproterenol are given in Table IV, which indicates that the maximal contractile response to forskolin was similar to maximal isoproterenol stimulation. Under certain conditions the contractile response to forskolin was additive to that of isoproterenol (Tables IV and V). When $10^{-5} \mathrm{M}$ isoproterenol doses were repeated $30 \mathrm{~min}$ after the initial exposure, a very little contractile effect was noted. If $10^{-5} \mathrm{M}$ forskolin was then added after the response to the 
Table III. Effect of Isoproterenol and Forskolin Alone or in Combination on Substrate (MgATP) and $\mathrm{Mg}^{2+}$ Kinetics, Mean \pm SEM of Preparations Derived from Three Failing Left Ventricles

\begin{tabular}{|c|c|c|c|c|c|c|}
\hline \multirow[b]{2}{*}{ Agonist } & \multicolumn{2}{|l|}{ MgATP } & \multicolumn{2}{|l|}{$\mathrm{Mg}^{2+}$} & \multicolumn{2}{|c|}{$\begin{array}{l}\text { Incremental increase in } V_{\text {max }} \\
\text { (agonist } V_{\max } \div \mathrm{H}_{2} \mathrm{O} V_{\max } \text { ) }\end{array}$} \\
\hline & $K_{\mathrm{m}}$ & $V_{\max }$ & $K_{\mathrm{m}}$ & $V_{\max }$ & MgATP & $\mathrm{Mg}^{2+}$ \\
\hline$M$ & $m M$ & pmol cAMP $\cdot \mathrm{min}^{-1} \cdot \mathrm{mg}^{-1}$ & $m M$ & pmol cAMP. $\mathrm{min}^{-1} \cdot m g^{-1}$ & & \\
\hline $\mathrm{H}_{2} \mathrm{O}$ & $0.051 \pm 0.017$ & $17.54 \pm 6.39$ & $2.35 \pm .72$ & $48.45 \pm 9.48$ & & \\
\hline Iso, $3 \times 10^{-7}$ & $0.083 \pm 0.015$ & $42.40 \pm 13.76$ & $1.24 \pm .33$ & $80.67 \pm 18.70$ & $2.56 \pm 0.64$ & $1.87 \pm 0.66$ \\
\hline Iso, $10^{-4}$ & $0.100 \pm 0.009$ & $71.32 \pm 18.66$ & $0.58 \pm .05$ & $93.96 \pm 27.52$ & $4.53 \pm 0.90$ & $2.26 \pm 0.99$ \\
\hline $\begin{array}{l}\text { FRSK, } 10^{-7} \\
\text { Iso, } 3 \times 10^{-7} \\
\quad+\text { FRSK }\end{array}$ & $0.105 \pm 0.005$ & $85.85 \pm 17.45$ & $1.30 \pm .05$ & $192.64 \pm 41.56$ & $5.26 \pm 1.00$ & $4.36 \pm 1.29$ \\
\hline $\begin{array}{c}10^{-7} \\
\text { Iso, } 10^{-4} \\
+ \text { FRSK }\end{array}$ & $0.091 \pm 0.028$ & $131.35 \pm 41.96$ & $0.99 \pm .26$ & $222.22 \pm 43.00$ & $7.97 \pm 0.91$ & $5.14 \pm 1.68$ \\
\hline $10^{-7}$ & $0.173 \pm 0.061$ & $268.02 \pm 105.93$ & $0.73 \pm .20$ & $250.99 \pm 38.15$ & $15.54 \pm 1.79$ & $5.81 \pm 1.80$ \\
\hline
\end{tabular}

Iso, isoproterenol; FRSK, forskolin.

second dose of isoproterenol had peaked, an increase in tension that was greater than the initial response to isoproterenol was achieved. However, if forskolin was the initial agonist given, the response to isoproterenol after a second dose of forskolin did not produce a greater effect than the initial forskolin response (Table V). Mean additivity data for forskolin addition to isoproterenol are given in Table IV.

Hemodynamic effects of forskolin in the open chest dog. To assess the hemodynamic effects in an in vivo setting, we evaluated the effects of forskolin in anesthesized and instrumented open-

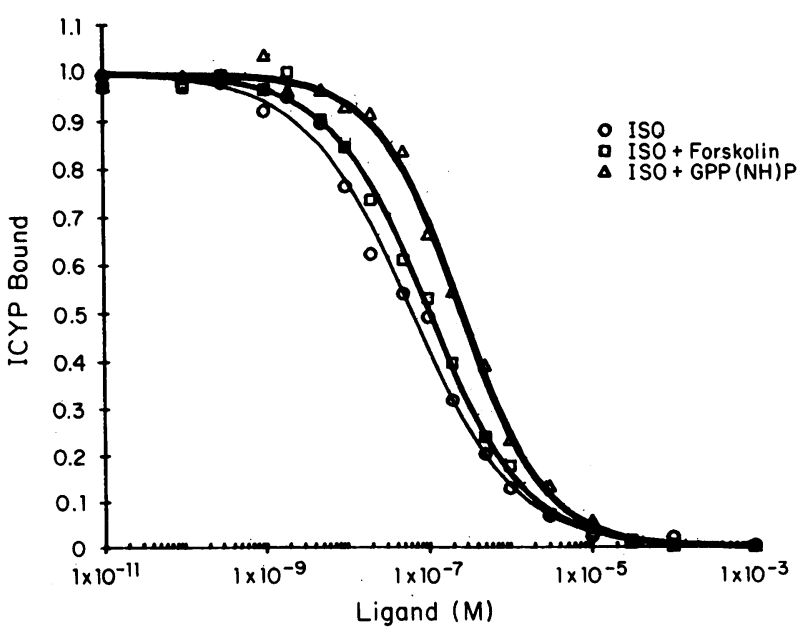

Figure 6. Effect of $10^{-5} \mathrm{M}$ forskolin or $10^{-4} \mathrm{M} \mathrm{Gpp}(\mathrm{NH}) \mathrm{p}$ on the isoproterenol (ISO)-ICYP competition curve in guinea pig myocardial membranes, individual experiment. ICYP concentration was $50 \mathrm{pM}$, receptor concentration was $3.1 \mathrm{pM} . y$ axis is fraction of ICYP bound; $x$ axis is isoproterenol \pm additions. chest dogs (Figs. 9 and 10). Forskolin produced similar effects to isoproterenol: dose-related increases in heart rate (Fig. $9 \mathrm{~A}$ ), cardiac output (Fig. $9 \mathrm{~B}$ ) and $\mathrm{dP} / \mathrm{dt}$ (Fig. $9 \mathrm{C}$ ), and dose-related decreases in mean arterial pressure (Fig. $10 \mathrm{~A}$ ), peripheral resistance (Fig. $10 \mathrm{~B}$ ), and left atrial pressure (Fig. $10 \mathrm{C}$ ). As for isolated muscle responses, forskolin proved less potent than isoproterenol on a molar basis, by 7.5- (blood pressure) to 63(cardiac output) fold.

With the exception of cardiac output and left atrial pressure, maximal effects of forskolin were equivalent to those of isoproterenol. The relatively lesser stimulation of cardiac output by forskolin may have been due to a reduction of left ventricular filling pressure by forskolin, as forskolin reduced left atrial pressure and isoproterenol did not (Fig. $10 \mathrm{C}$ ).

\section{Discussion}

We evaluated the pharmacology and inotropic potential of forskolin, a diterpene derivative of Coleus forskohlii $(1,21)$. Forskolin proved to be a potent activator of human myocardial adenylate cyclase, and produced stimulation over a similar range as did isoproterenol. The degree of maximal activation of adenylate cyclase was an impressive 26-fold greater than basal activity, and 4.8-6.1-fold greater than maximal isoproterenol stimulation.

The mechanism by which forskolin activates human myocardial adenylate cyclase could be distinguished from effects of isoproterenol and fluoride ion $\left(\mathrm{F}^{-}\right)$. Forskolin's action was beyond the $\beta$-adrenergic receptor, in agreement with a previous investigation in rat myocardial membrane preparations (1). In contrast to isoproterenol, forskolin did not require guanine nucleotides for activation and was not blocked by propranolol, in agreement with previous studies $(1,3,21)$. The slight inhibition of forskolin activity by the nonhydrolyzable GTP analogue 


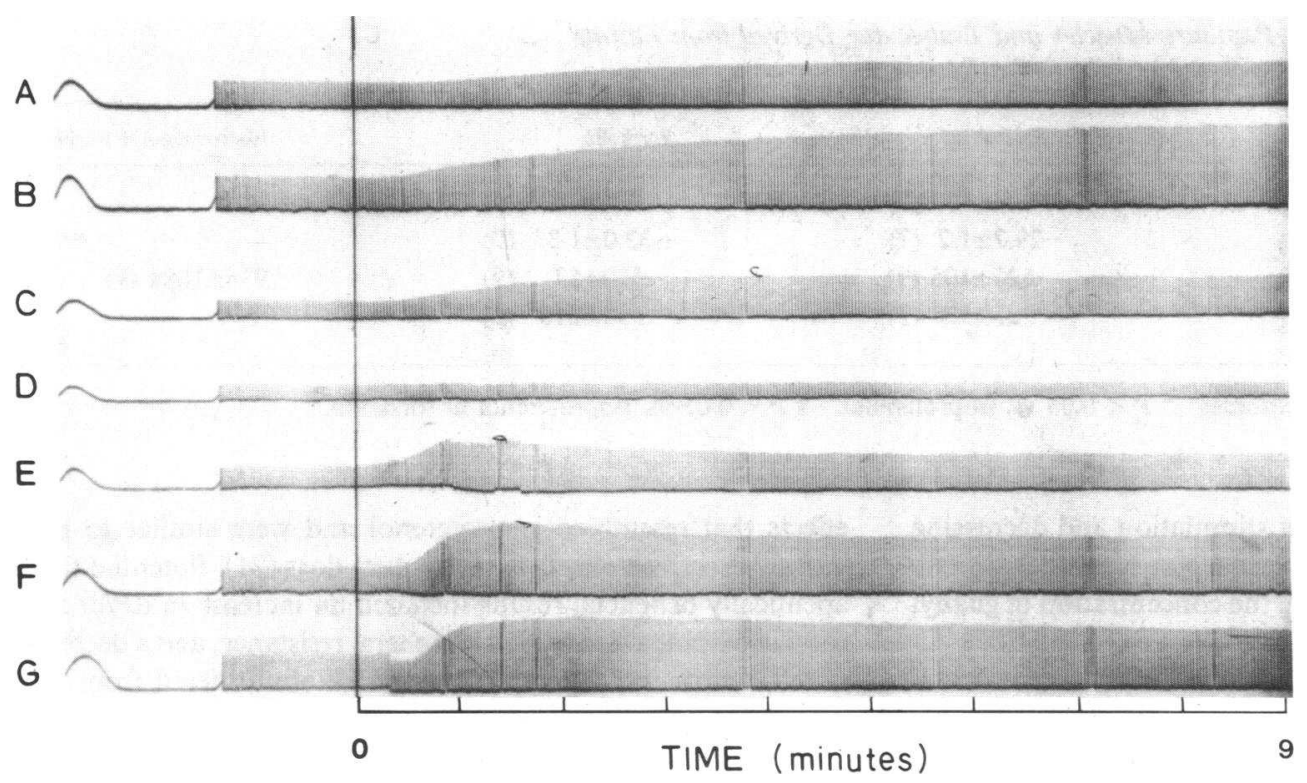

Figure 7. Effect of forskolin $\left(10^{-5} \mathrm{M}, A-C\right)$ or isoproterenol $\left(10^{-5} \mathrm{M}, E-G\right)$ on milligrams of tension in seven right ventricular trabecular preparations from a single failing human heart. $D$ is a control given vehicle alone. Note the longer time to peak effect for forskolin. See Methods and Table IV for further details.
$\mathrm{Gpp}(\mathrm{NH}) \mathrm{p}$ is consistent with previous work that describes an inhibitory role for $\mathrm{Gpp}(\mathrm{NH}) \mathrm{p}$ regulation of adenylate cyclase activity (31). Our data are therefore consistent with a primary effect of forskolin on $\mathrm{C}$, the catalytic subunit of adenylate cyclase. However, since we did not perform extensive pharmacologic or biochemical analyses of potential forskolin- $\mathrm{N}$ site interactions, our data do not exclude an additional mechanism of action involving effects on $\mathrm{N}$, as has been described in intact cells (30).

The effect of forskolin on substrate and $\mathbf{M g}^{2+}$ kinetics differed from isoproterenol and $\mathrm{F}^{-}$in several respects. Unlike isoproterenol (32), the increase in substrate $V_{\max }$ produced by forskolin

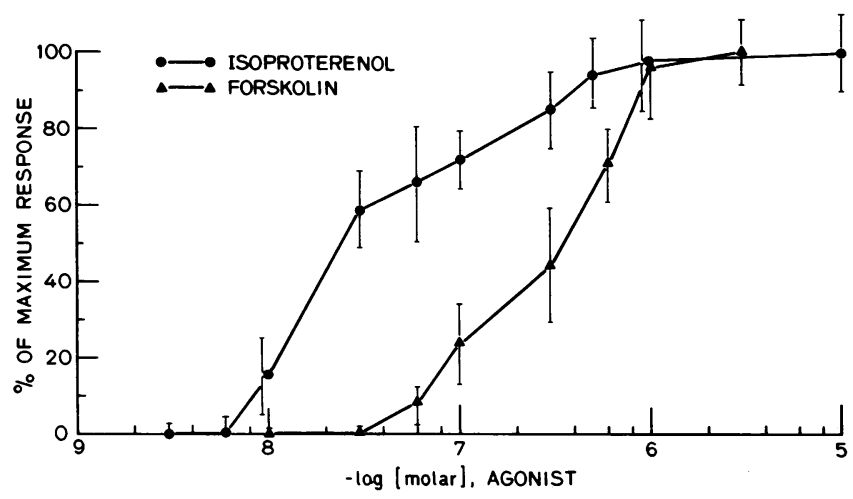

Figure 8. Human right ventricle. Dose-response curves for isoproterenol (๑) and forskolin $(\Delta)$ in isolated cardiac tissue derived from failing human hearts, stimulation of contractile force normalized to $100 \%=$ maximum effect. Each point is the mean \pm SEM of three experiments with three trabeculae used for each agonist in each experiment. $\mathrm{ED}_{50}$ 's are $2.4 \times 10^{-8} \mathrm{M}$ (isoproterenol) and $3.5 \times 10^{-7} \mathrm{M}$ (forskolin). was accompanied by a substantial increase in MgATP $K_{\mathrm{m}}$. This suggests that forskolin increases the number of substrate binding sites and also induces a conformational change in these sites. Unlike $\mathrm{F}^{-}$(32), forskolin decreases the $\mathrm{Mg}^{2+} K_{\mathrm{a}}$, in a manner similar to isoproterenol.

Stimulation of adenylate cyclase by forskolin was not decreased in membranes prepared from severely failing human left ventricle. In contrast, stimulation of cyclase by isoproterenol in these membranes was attenuated, secondary to the decreased $\beta$-receptor density. $\mathrm{F}^{-}$stimulation, like forskolin, was not different in failing vs. normally functioning myocardium. These data indicate that the catalytic subunit of adenylate cyclase is not affected by end-stage heart failure, and that full enzymatic stimulation may be achieved by agents that act primarily on this subunit.

When forskolin and receptor-coupled agonist stimulation was used in combination, supra-additive or synergistic effects were observed. This would be predicted from the known loci of these agents' sites of action, as in the effector pathway " $\mathrm{C}$," the catalytic moiety of cyclase is in series and distal to " $R$," the agonist receptor. Stimulation at $\mathbf{R}$ can therefore be multiplied by stimulative effects occurring at $\mathrm{C}$. In contrast, in human or guinea pig myocardial membranes, agents that act by parallel pathways, such as two receptor-coupled agonists, produce less than additive stimulation when added in combination (Lemmers, M., and M. Bristow, unpublished observations). The "in series" positioning of $R$ and $C$ in the effector pathway apparently accounted for the observed synergism, as forskolin did not alter the affinity of the $\beta$-receptor for isoproterenol, as has been reported in whole cell preparations (30), and forskolin did not affect receptor density. In membranes derived from failing human hearts, the end result of this $\beta$-agonist-forskolin synergism was to normalize the appearance of the isoproterenol dose-re- 
Table IV. Human Right Ventricular Papillary Muscles and Trabeculae Derived from Failing Human Hearts; Comparison of Isoproterenol and Forskolin Responses

\begin{tabular}{|c|c|c|c|}
\hline Parameter & Isoproterenol & Forskolin & Isoproterenol + forskolin \\
\hline Time to peak effect $(s)$ & $103 \pm 15$ & $971 \pm 418$ & - \\
\hline Change in time to peak tension (\%) & $-29.2 \pm 1.2(7)$ & $-32.0 \pm 1.3$ & - \\
\hline Maximum net increase in tension $(m g)$ & $520 \pm 105(9)$ & $530 \pm 57$ & $936 \pm 108 \ddagger(9)$ \\
\hline $\mathrm{ED}_{50}(n M)$ & $23 \pm 12$ & $350 \pm 210^{*}$ & - \\
\hline
\end{tabular}

Values are given $\pm \mathrm{SEM}$, with $n$ in parentheses ${ }^{*} P<0.05$ vs. isoproterenol. $\ddagger P<0.05$ vs. isoproterenol or forskolin.

sponse curve, by increasing the net stimulation and decreasing the $K_{\text {act }}$. In this regard the decrease in receptor-coupled hormone $K_{\mathrm{act}}$ is similar to effects of increasing the concentration of guanyl nucleotides $(32,33)$.

Substrate kinetic data revealed that the effects of isoproterenol and forskolin on substrate $V_{\max }$ were synergistic, which presumably somewhat explains the synergism of the pharmacologic response. The net effect of isoproterenol and forskolin in combination was therefore to markedly and synergistically increase the number of substrate binding sites, reduce substrate affinity, increase the $\mathrm{Mg}^{2+}$ catalytic binding site affinity, and increase the number of $\mathrm{Mg}^{2+}$ binding sites of the catalytic moiety of adenylate cyclase.

Forskolin was a potent and powerful positive inotropic agent in isolated tissue derived from failing human hearts, producing maximum effects that were similar to maximal isoproterenol responses. The reason why forskolin was not superior to isoproterenol in producing inotropic effects is not clear, since forskolin produced a much greater stimulation of adenylate cyclase than did isoproterenol. This disparity persists in the face of phosphodiesterase inhibition (unpublished observations) and thus is probably not due to increased turnover of cAMP in forskolin-treated hearts. The discrepancy between forskolin-related cyclase stimulation and inotropic response may relate to biochemical differences between intact tissue and membrane preparations, to differences in specific pools of cAMP that are actually available for augmenting the contractile response, or to difficulty with diffusion of forskolin through the myocardial cell membrane.

In an intact preparation forskolin produced hemodynamic effects that resembled isoproterenol and were similar to previously described effects in open-chest dogs (21). Potential therapeutically beneficial results included an increase in $\mathrm{d} P / \mathrm{d} t$ and cardiac output, a decrease in peripheral resistance, and a decrease in left ventricular filling pressure. Forskolin differed from isoproterenol only in producing a more profound effect on left atrial pressure. Therefore, forskolin is a positive inotropic agent that also reduces afterload and preload, all of which are beneficial pharmacologic properties in the treatment of congestive heart failure.

Our motivation for characterizing the cardiovascular pharmacology of forskolin is that we felt that a catecholamine-like agent that was not activated through receptors and that acted directly on the catalytic subunit of myocardial adenylate cyclase would be a potentially useful drug that would not be affected by subsensitivity phenomena. That is, patients with severe congestive heart failure already are subsensitive to the effects of catecholamines through down-regulation of $\beta$-adrenergic receptors $(14,22,23)$, and treatment with $\beta$-agonists may further down-regulate receptors $(12,14-18)$ and/or uncouple them from adenylate cyclase (15-18). Our data in membrane preparations indicate that forskolin should be devoid of this problem, as it acts directly on $\mathrm{C}$ without any apparent interaction with $\mathrm{R}$ or $\mathrm{N}$. Moreover, myocardial membrane preparations that exhibited catecholamine subsensitivity remained fully responsive to the adenylate cyclase stimulatory action of forskolin.

Although in this and other $(1,2)$ investigations forskolin did not alter events occurring at $\mathrm{R}$, it apparently may do so in intact cells through some type of effect on $N(30)$. In these studies on S49 cells, Darfler et al. (30) described forskolin-me-

Table V. Effect of Sequential Addition of Forskolin or Isoproterenol in Human Right Ventricular Papillary Muscles and Trabeculae, Single Experiment in Eight Muscle Preparations Derived from Failing Human Heart

\begin{tabular}{lcccc}
\hline & $\begin{array}{l}\text { Peak effect, } \\
\text { ist dose }\end{array}$ & $\begin{array}{l}\text { 30 min after } \\
\text { peak effect }\end{array}$ & \multicolumn{1}{c}{$\begin{array}{l}\text { Repeat } \\
\text { drug }\end{array}$} & $\begin{array}{r}\text { Addition of } \\
\text { opposite drug }\end{array}$ \\
\hline Group 1 $(n=4) 10^{-5} \mathrm{M}$ forskolin added first & $830 \pm 413$ & $850 \pm 218$ & $700 \pm 158$ & $890 \pm 217$ \\
Group 2 $(n=4) 10^{-5}$ isoproterenol added first & $1,100 \pm 234$ & $600 \pm 108$ & $650 \pm 119$ & $1830 \pm 149$
\end{tabular}

Net milligram tension increase (drug effect - base line \pm SEM). 

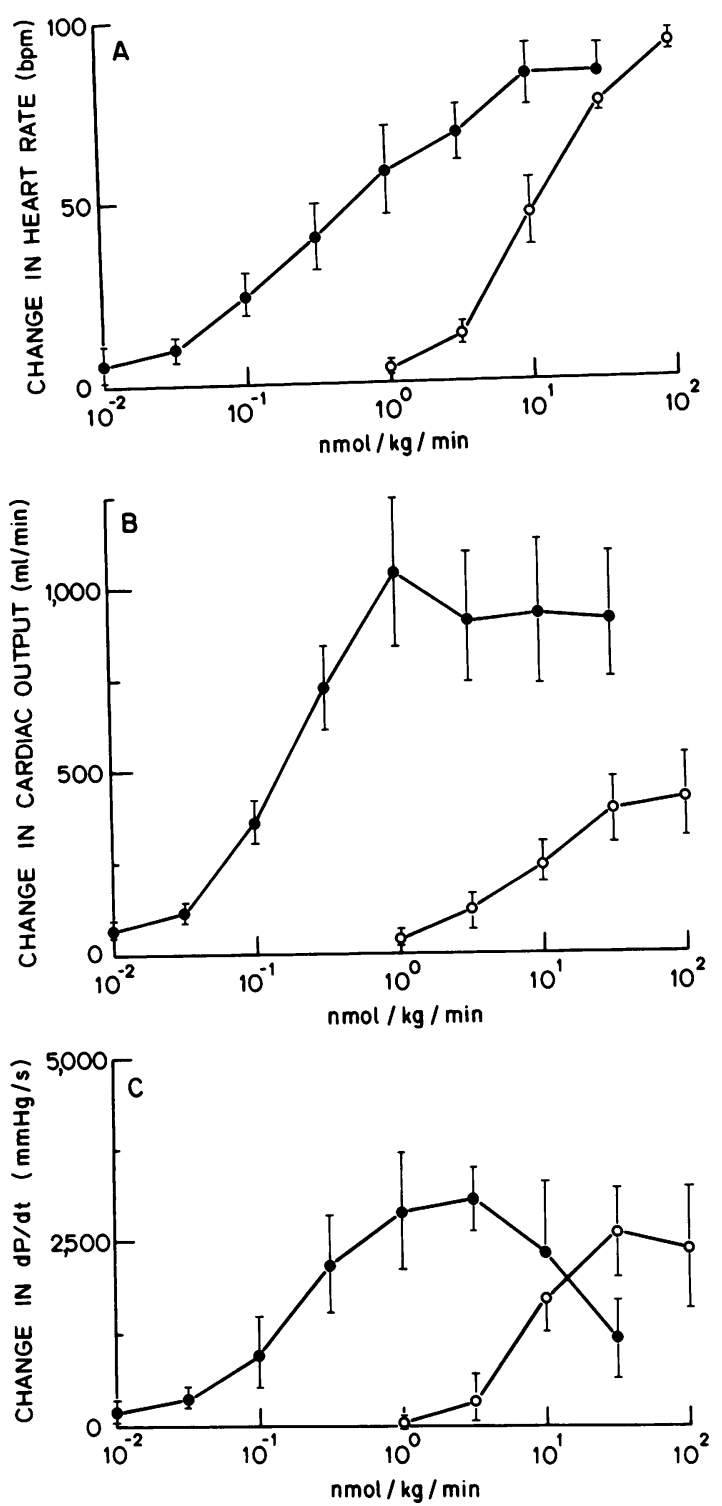

Figure 9. Hemodynamic effects of isoproterenol (•) and forskolin (0) in instrumented open-chest dogs, with data expressed as change from base-line values. Points are mean \pm SEM of four experiments. Respective base-line values for isoproterenol and forskolin are: $A, 169 \pm 5$ and $179 \pm 1$ beats per minute (bpm), $B, 1,100 \pm 134$ and $1,194 \pm 165$ $\mathrm{ml} / \mathrm{min} ; C, 2,100 \pm 300$ and $2,525 \pm 364 \mathrm{mmHg} / \mathrm{s}$.

diated increased coupling of $\beta$-receptors to adenylate cyclase, as the proportion of receptors in a high affinity state was increased in the presence of forskolin. This property may have been the explanation for the restoration of the isoproterenol response by forskolin in isolated muscle preparations, where, after a relatively ineffective second dose of isoproterenol, the response to forskolin was greater than would be expected from addition to the attenuated isoproterenol response. If forskolin were capable of preventing or reversing receptor-cyclase uncoupling, the presence of this property and the property of additivity or synergism
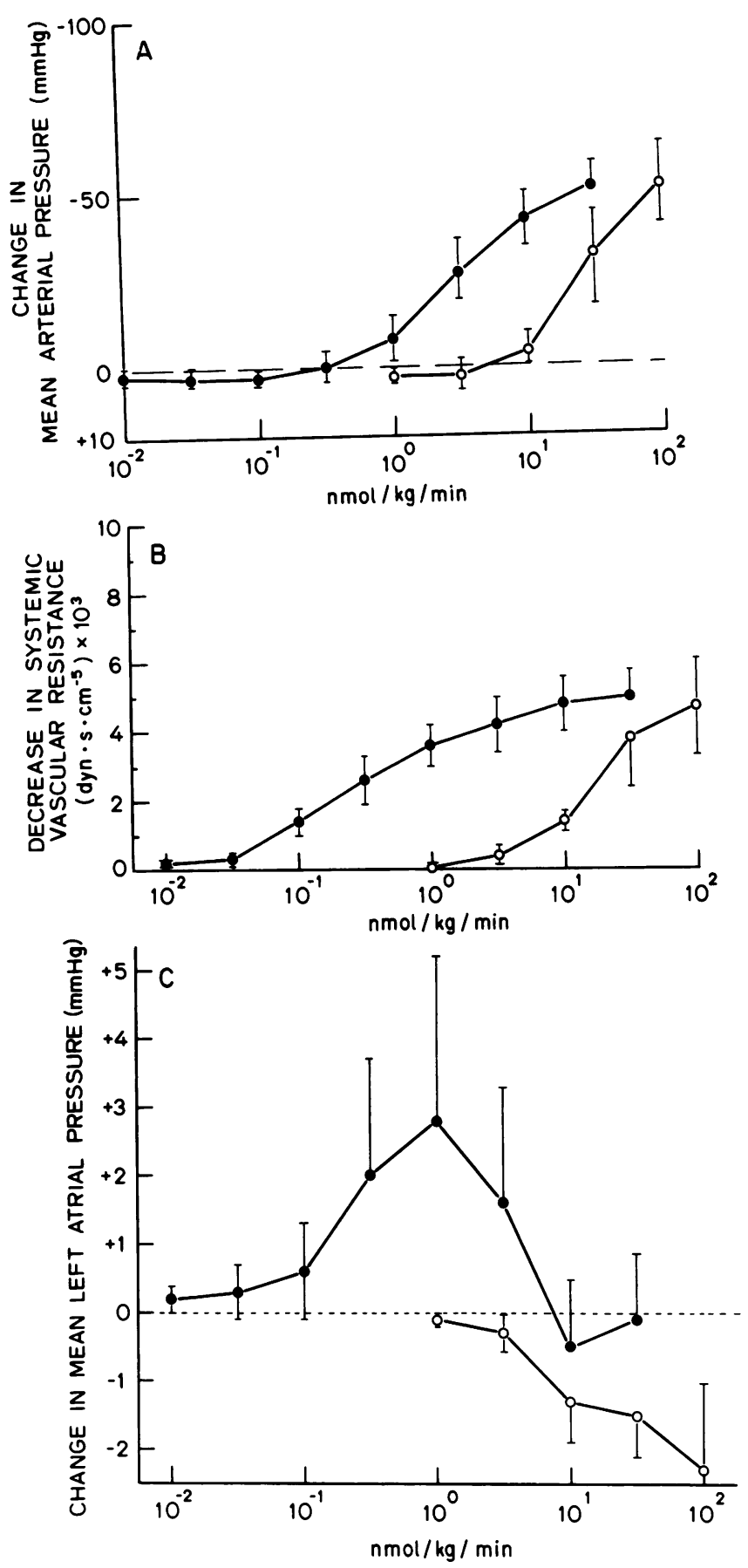

Figure 10. Hemodynamic effects of isoproterenol $(\bullet)$ and forskolin (o) in instrumented open-chest dogs, with data expressed as change from base-line values. Points are mean \pm SEM of four experiments. Respective base-line values for isoproterenol and forskolin are: $A$, $90 \pm 8$ and $106 \pm 13 \mathrm{mmHg} ; B, 6,782 \pm 842$ and $7,624 \pm 1,671$ $\left(\right.$ dyn $\left.\cdot \mathrm{s} \cdot \mathrm{cm}^{-5}\right) \times 10^{-3} ; C, 8 \pm 4$ and $8 \pm 4 \mathrm{mmHg}$.

when forskolin is used in combination with hormone agonists might make forskolin an ideal agent to be used in combination with a catecholamine. 
Finally, although the consensus of opinion favors a regulatory role for cAMP in modulating myocardial contractility $(4,5)$, recent data have raised questions as to whether adenylate cyclase stimulation mediates the positive inotropic effects of catecholamines in human cardiac tissue (34). Our results of forskolin activation of human myocardial adenylate cyclase and stimulation of contractility therefore serve to support the hypothesis that cAMP is the second messenger for positively inotropic $\beta$ agonists.

Obviously, as a nonspecific activator of adenylate cyclase, forskolin may prove to be too toxic to be used clinically. However, it does appear to have many pharmacologically and hemodynamically ideal properties, and therefore may prove useful as a prototype for the development of similar agents that would have a more selective effect on myocardial adenylate cyclase. The results of this study suggest that some degree of myocardial selectivity could be obtained by combination with a $\beta_{1}$-agonist, and on theoretical grounds selectivity could also be achieved by combining forskolin with a myocardial-specific phosphodiesterase inhibitor. The positive chronotropic effects of the drug observed in open-chest, anesthetized dogs may prove to be limiting, but its chronotropic effects may not be as marked in subjects with heart failure and elevated peripheral resistance and left atrial pressure. In fact, a previous study in isolated guinea pig heart suggested a preferential effect on force development compared with heart rate (21).

In summary, forskolin is a potent, powerful activator of human myocardial adenylate cyclase. Its locus of effect is beyond the level of hormone receptors and in series with receptor-coupled stimulation, presumably through a direct action on the catalytic subunit of adenylate cyclase. This positioning of forskolin's effect imparts synergism to the combination of hormone and forskolin, and may mean that physiologic effects of forskolin are devoid of subsensitivity. Forskolin is a potent positive inotropic agent in isolated tissue derived from failing human hearts, and its hemodynamic effects in intact dogs suggest that it or other members of this unique class of compounds may be potentially useful in the treatment of congestive heart failure.

\section{Acknowledgment}

This work was supported in part by NHLBI 13108-13.

\section{References}

1. Metzger, H., and E. Lindner. 1981. The positive inotropic-acting forskolin, a potent adenylate cyclase activator. Arzneim. Forsch. 31:12481250.

2. Seamon, K. B., W. Padgett, and J. W. Daly. 1981. Forskolin: unique diterpene activator of adenylate cyclase in membranes and in intact cells. Proc. Natl. Acad. Sci. USA. 78(6):3363-3367.

3. Seamon, K., and J. W. Daly. 1981. Activation of adenylate cyclase by the diterpene forskolin does not require the guanine nucleotide regulatory protein. J. Biol. Chem. 256(19):9799-9801.

4. Epstein, S. E., C. L. Skelton, G. S. Levey, and M. Entman. 1970.
Adenyl cyclase and myocardial contractility. Ann. Intern. Med. 72:561578.

5. Drummond, G. E., and D. L. Severson. 1979. Cyclic nucleotides and cardiac function. Circ. Res. 44(2):145-152.

6. Bristow, M. R., N. E. Kantrowitz, R. Ginsburg, and M. B. Fowler. 1984. $\beta$-adrenergic function in heart muscle disease and heart failure. J. Mol. Cell. Cardiol. In press.

7. Eichna, L. W. 1967. The treatment of cardiogenic shock. Am. Heart J. 76:848-852.

8. Goldberg, L. I. 1974. Dopamine-clinical uses of an endogenous catecholamine. N. Engl. J. Med. 291(14):707-710.

9. Applefeld, M. M., K. A. Newman, W. R. Grove, F. J. Sutton, D. S. Roffman, W. P. Reed, and S. E. Linberg. 1983. Intermittent, continuous outpatient dobutamine infusion in the management of congestive heart failure. Am. J. Cardiol. 51:455-458.

10. Leier, C. V., and D. V. Unverferth. 1983. Dobutamine. Ann. Intern. Med. 99:490-496.

11. Erbel, R., J. Meyer, H. Lambertz, P. Schweizer, W. Foelker, W. Krebs, G. Braun, and S. Effert. 1982. Hemodynamic effects of prenalterol in patients with ischemic heart disease and congestive cardiomyopathy. Circulation. 66(2):361-369.

12. Colucci, W. S., R. W. Alexander, G. H. Williams, R. E. Rude, B. L. Holman, M. A. Constam, J. Wynne, G. H. Mudge, Jr., and E. Braunwald. 1981. Decreased lymphocyte beta-adrenergic-receptor density in patients with heart failure and tolerance to the beta-adrenergic agonist pirbuterol. N. Engl. J. Med. 305(4):185-190.

13. Weber, K. T., V. Andrews, J. S. Janicki, M. Likoff, and N. Reicher. 1982. Pirbuterol, an oral beta-adrenergic receptor agonist, in the treatment of chronic cardiac failure. Circulation. 66(6):1262-1267.

14. Ginsburg, R., L. J. Esserman, and M. R. Bristow. 1983. Myocardial performance and extracellular ionized calcium in a severely failing human heart. Ann. Intern. Med. 98(5):603-606.

15. Tse, J., J. R. Powell, C. A. Baste, R. E. Priest, and J. F. Kuo. 1979. Isoproterenol-induced cardiac hypertrophy: modifications in characteristics of $\beta$-adrenergic receptor, adenylate cyclase, and ventricular contraction. Endocrinology. 105:246-255.

16. Bobik, A., J. H. Campbell, V. Carson, and G. R. Campbell. 1981. Mechanism of isoprenaline-induced refractoriness of the $\beta$-adrenoceptor-adenylate cyclase system in chick embryo cardiac cells. $J$. Cardiovasc. Pharmacol. 3:541-553.

17. Marsh, J. D., W. H. Barry, E. J. Neer, R. W. Alexander, and T. W. Smith. 1980. Desensitization of chick embryo ventricle to the physiological and biochemical effects of isoproterenol. Evidence for uncoupling of the $\beta$-receptor-adenylate cyclase complex. Circ. Res. 47(4):493-501.

18. Kenakin, T. P., and R. M. Ferris. 1983. Effects of in vivo $\beta$ adrenoceptor down-regulation on cardiac responses to prenalterol and pirbuterol. J. Cardiovasc. Pharmacol. 5:90-97.

19. Su, Y. F., T. K. Harden, and J. P. Perkins. 1980. Catecholaminespecific desensitization of adenylate cyclase. J. Biol. Chem. 255:74107419.

20. Johnson, G. L., H. R. Kaslow, Z. Farfel, and H. R. Bourne. 1980. Genetic analysis of hormone-sensitive adenylate cyclase. Adv. Cyclic Nucl. Res. 13:1-37.

21. Lindner, E., A. N. Dohadwalla, and B. K. Bhattacharya. 1978. Positive inotropic and blood pressure lowering activity of a diterpene derivative isolated from coleus forskolii: forskolin. Arzneim. Forsch. 28(1):284-289.

22. Bristow, M. R., R. Ginsburg, W. Minobe, R. S. Cubicciotti, W. S. Sageman, K. Lurie, M. E. Billingham, D. C. Harrison, and E. B. Stinson. 1982. Decreased catecholamine sensitivity and $\beta$-adrenergic- 
receptor density in failing human hearts. N. Engl. J. Med. 307:205211.

23. Ginsburg, R., M. R. Bristow, M. E. Billingham, E. B. Stinson, J. S. Schroeder, and D. C. Harrison. 1983. Study of the normal and failing isolated human heart: decreased response of failing heart to isoproterenol. Am. Heart J. 106:535-540.

24. Engel, G., D. Hoyer, R. Berthod, and H. Wagner. 1981. $( \pm)\left[{ }^{125}\right.$ Iodo]cyanopindolol, a new ligand for $\beta$-adrenoceptors: identification and quantitation of subclasses of $\beta$-adrenoceptors in guinea pig. Naunyn-Schmiedeberg's Arch. Pharmacol. 317:277-285.

25. Hoyer, D., G. Engel, and R. Berthold. 1982. Binding characteristics of $(+),( \pm)$ - and $(-)-\left[{ }^{125}\right.$ Iodo]cyanopindolol to guinea-pig left ventricle membranes. Naunyn-Schmiedeberg's Arch. Pharmacol. 318:319-329.

26. Lowry, O. H., N. J. Rosebrough, A. L. Farr, and R. J. Randall. 1951. Protein measurement with the Folin phenol reagent. J. Biol. Chem. 193:265-275.

27. Scatchard, G. 1949. The attraction of proteins for small molecules and ions. Ann. NY Acad. Sci. 51:660-672.

28. Cornish-Bowden, A. 1979. Fundamentals of Enzyme Kinetics. Butterworth Publishers, Woburn, MA.
29. De Lean, A., P. J. Munson, and D. Rodbard. 1978. Simultaneous analysis of families of sigmoidal curves: application to bioassay, radioligand assay, and physiological dose-response curves. Am. J. Physiol. 235(2):E97-E102.

30. Darfler, F. J., L. C. Mahan, A. M. Koachman, and P. A. Insel. 1982. Stimulation by forskolin of intact $\mathbf{S} 49$ lymphoma cells involves the nucleotide regulatory protein of adenylate cyclase. J. Biol. Chem. 257(20):11901-11907.

31. Hudson, T. H., and J. N. Fain. 1983. Forskolin-activated adenylate cyclase. Inhibition by guanyl-5'-yl imidodiphosphate. J. Biol. Chem. 258(16):9755-9761.

32. Bristow, M. R., R. Cubicciotti, R. Ginsburg, E. B. Stinson, and C. Johnson. 1982. Histamine-mediated adenylate cyclase stimulation in human myocardium. Mol. Pharmacol. 21:671-679.

33. Ross, E. M., M. E. Maguire, T. W. Sturgill, R. L. Biltonen, and A. G. Gilman. 1977. Relationship between the $\beta$-adrenergic receptor and adenylate cyclase. J. Biol. Chem. 252:5761-5775.

34. Waelbroeck, M., G. Taton, M. Delhaye, P. Chatelain, J. C. Amus, R. Pochet, J. L. Leclerc, J. M. De Smet, P. Robberecht, and J. Christophe. 1983. The human heart beta-adrenergic receptors. II. Coupling of beta ${ }_{2}$-adrenergic receptors with the adenylate cyclase system. Mol. Pharmacol. 24:174-182. 